\title{
Aneurysmal subarachnoid haemorrhage: outcomes of early rehabilitation after surgical repair of ruptured intracranial aneurysms
}

\author{
B M Saciri, N Kos
}

See end of article for authors' affiliations

Correspondence to: Dr B M Saciri, Jakceva 40/46, 1000 Ljubljana, Slovenia;

vali.branka@siol.net

Received 13 March 2001

In revised form 3

September 2001

Accepted 14 November
Objectives: The aim was to analyse functional and cognitive outcomes in patients receiving early rehabilitation treatment after surgery for aneurysmal subarachnoid haemorrhage (SAH).

Methods: The assessment protocol included all relevant clinical data, the Hunt-Hess scale, the functional independence measure (FIM), and the mini mental state examination (MMSE).

Results: Of 59 patients included in the study, 52.5\% (31) were men and $47.5 \%(28)$ were women. The patients' average age was 52 years, and $57.6 \%$ were employed at the time of the aneurysm rupture. The mean duration of hospital stay was 25 days; $67.8 \%(40)$ of the patients were discharged home. At discharge, $72.7 \%$ of the patients were without any motor impairment, but $59.6 \%$ showed cognitive impairment. By the time of discharge, $43.4 \%$ (23) of the patients had attained independence in activites of daily living, $18.9 \%$ (10) needed intermittent supervision, and $37.7 \%(20)$ required constant supervision in the performance of these activities.

Conclusions: The severity of cognitive impairment has predictive value for the functional status and the level of supervision required at discharge.
S ubarachnoid haemorrhage (SAH) is a common and often devastating occurrence. This pathology accounts for $5 \%-10 \%$ of all strokes, affecting mostly people in the 5 th decade of life, at the peak of their productivity. ${ }^{1-4}$ The consequences of SAH are motor and cognitive impairments which result in social and vocational disabilities, and these have a significant impact on the quality of the patient's life and his or her social integration..$^{5-7}$

By its nature, SAH involves the likelihood of diffuse disruption of the brain cortex, at least in the period immediately after haemorrhage. This has been attributed to the neurotoxic effects of the widespread subarachnoid blood extravasation. ${ }^{8}$ The presence of blood in the subarachnoid space seems to affect the higher brain functions. ${ }^{9}{ }^{10}$ In addition, there may be more localised areas of disruption as a consequence of vasospasm and ischaemia that can develop over a period of several days after SAH. Many authors have found that most survivors of SAH make an excellent neurological recovery, but never fully regain their premorbid status due to cognitive and psychosocial deficits. ${ }^{1-14}$ Cognitive, behavioural, and social impairment can lead to patients experiencing difficulty with reintegration into the social environment, often despite the physical outcome.

Most patients in Slovenia who survive a spontaneous SAH are admitted to the University Medical Centre Ljubljana for treatment. Surgery for SAH due to a ruptured intracranial aneurysm is performed as early as feasible.

This study was conducted at the Department of Neurosurgery, University Medical Centre Ljubljana, with the aim of analysing the functional and cognitive outcomes in patients receiving early rehabilitation after surgery for aneurysmal subarachnoid haemorrhage (SAH), determining the need for further rehabilitation with the aid of functional assessment after discharge from hospital, and establishing the usefulness of the proposed method of assessment in everyday practice with this group of patients.

\section{SUBJECTS AND METHODS}

All patients admitted to the Department of Neurosurgery and operated on for aneurysmal SAH over a period of 12 months participated in the study. The study population consisted of 59 adult patients.

Data were gathered throughout the study (prospective database) and included age, sex, level of education, premorbid employment status, concomitant illnesses and risk factors, type and site of the aneurysm, time from the onset of symptoms to surgery, time from admission to hospital to time of surgery, total number of inpatient days, and duration of inpatient rehabilitation in days. The patient's clinical status on admission was assessed using the Hunt-Hess five grade scale, describing the patient's condition immediately after SAH. In all patients, the diagnosis of SAH due to a ruptured aneurysm was confirmed by clinical history, CT, and angiography. Motor impairment was determined by an experienced physiatrist at the time of admission to the rehabilitation programme and at discharge from hospital.

Functional status was assessed using the functional independence measure (FIM) on admission to rehabilitation and at discharge from hospital. The FIM relates impairment to disability and correlates with the degree of supervision. ${ }^{26} 1516$ Functional status is measured on a scale of 1 (totally dependent) to 7 (independent) for 18 categories (tasks such as performance in self care, sphincter control, transfers and locomotion, communication, and social cognition). By adding the points for each item, the possible total score ranges from 18 (lowest) to 126 (highest level of independence). The FIM may be separated into motor ( 13 items) and cognitive (five items) scales. Functional gains were determined by comparing admission and discharge FIM scores. Duration of inpatient rehabilitation was defined as the number of days on which intensive rehabilitation was provided. The mean gain was calculated by dividing the mean total FIM score change by the mean duration of rehabilitation. This figure multiplied by seven represents gain in FIM points a week.

Abbreviations: $\mathrm{SAH}$, subarachnoid haemorrhage; FIM, functiona independence measure; MMSE, mini mental state examination 
Table 1 Clinical condition at admission according to the Hunt-Hess scale

\begin{tabular}{ll}
\hline Hunt-Hess grade* & Patients (n (\%)) \\
\hline I & $24(40.7)$ \\
II & $10(16.9)$ \\
III & $22(37.3)$ \\
IV & $3(5.1)$ \\
V & 0
\end{tabular}

*Grade I,mild headache, slight nuchal rigidity; grade II, moderate to severe headache, nuchal rigidity, no neurological deficit other than cranial nerve palsy; grade III, drowsiness/confusion, mild focal neurological deficit; grade IV, stupor, moderate-severe hemiparesis; grade $\mathrm{V}$, coma, decerebrate posturing.

\begin{tabular}{ll} 
Table 2 & \multicolumn{1}{c}{ Localisation of the ruptured aneurysm } \\
\hline Arterial localisation of the ruptured aneurysm & Patients (n (\%)) \\
\hline Anterior communicating & $26(44.1)$ \\
Middle cerebral & $17(28.8)$ \\
Internal carotid & $11(18.6)$ \\
Basilar & $5(8.5)$ \\
Posterior communicating & $2(6.8)$ \\
Anterior cerebral & $2(3.4)$ \\
Posterior cerebral & $1(1.7)$ \\
Posterior inferior cerebellar & $1(1.7)$
\end{tabular}

Cognitive impairment (time and place orientation, memory deficits, and appropriate responding) was assessed by a physician at the beginning of the rehabilitation programme and at discharge from hospital. Cognitive status at discharge was assessed also by means of the mini mental state examination (MMSE). The MMSE is a test consisting of 30 questions. Conducting the test does not require much time, and does not tire the patient. It is an orientational test for determining the likelihood of the presence of cognitive deficits in patients (screening). In the assessment, each correct answer is given one point. The total of points provides the final result. The maximum number of points is 30. In interpreting the MMSE data, we followed the guidelines provided by Slovenian authors. ${ }^{17}$

The degree of supervision needed at discharge was determined by the rehabilitation team and ranged from constant supervision (24 hours a day) to intermittent supervision (the patient could be left alone for several hours) or independence with no supervision required.

\section{Ethics}

The research design was approved by the medical ethics committee of the Republic of Slovenia.

\section{RESULTS}

Of the 59 patients with SAH due to a ruptured intracranial aneurysm included in the study, $52.5 \%$ (31) were men and
$47.5 \%(28)$ were women. The average age was 52 years, with a range from 21 to 82 years. Most patients $(62.7 \%)$ had a secondary school education, and $57.6 \%$ (34) were employed at the time of the aneurysm rupture.

Of the 59 patients, $54.2 \%$ (32) were admitted to hospital within a day of the onset of symptoms. All patients were treated operatively 0 to 29 days after the onset of symptoms; $72.8 \%$ underwent surgery within 24 hours of admission to the Department of Neurosurgery.

On admission to the Department of Neurosurgery, $57.6 \%$ (34) of the patients showed no impairment of consciousness. Their clinical condition was Hunt-Hess grade 1 or 2 (table 1). Motor impairment was found in $42.4 \%$ (25) of the patients.

Evaluation of the risk factors identified in the group showed that $40.7 \%$ (24) of the patients were smokers at the time of $\mathrm{SAH}, 50.8 \%$ (30) had arterial hypertension, $13.5 \%$ (eight) had concomitant illnesses, $11.9 \%$ (7) regularly consumed alcohol, and 3.3\% (two) used oral contraceptives.

The localisations of the lesions involved are shown in the table $2 ; 51.6 \%$ of the aneurysms were right sided and $48.4 \%$ were left sided. Seven patients (11.9\%) had more than one aneurysm.

The mean duration of hospital stay was 25 days (range 8-105 days). Patients with a ruptured aneurysm of the basilar or posterior communicating artery had the longest hospital stays (up to 105 days). The patients who showed motor impairment at the time of initial assessment stayed in hospital on average 36 days.

The rehabilitation programme was begun 2 to 7 days after operation and was given by the rehabilitation team, consisting of a physiatrist, physical therapist, occupational therapist, and respiratory therapist. The mean duration of early inpatient rehabilitation was 21 days (range 6-85 days) for all patients studied.

Results of the FIM assessment at admission and at discharge from hospital are presented in table 3. Of the 59 patients participating in the study, six did not complete the assessment because of transfer to other hospital departments (two) or death (four).

At discharge from hospital, $60.4 \%$ (32) of the 53 patients tested were not yet oriented to time, person or situation.

According to the MMSE test at discharge, $40.4 \%$ (19) of the examined patients (47) showed no impairment of cognitive functioning; $23.4 \%$ (11) showed a mild cognitive deficit, and $36.2 \%$ (17) had scores indicating severe cognitive impairment. Six patients (out of 53) were unable to complete the MMSE because of aphasia (five) or physical incapacity (one). As indicated by the MMSE scores, memory problems and attention disorders were the most frequent cognitive deficits resulting from SAH. The patients who showed a severe cognitive deficit according to MMSE required on average 23 days of rehabilitation.

By the time of discharge, 43.4\% (23) of the 53 evaluated patients had attained independence in activities of daily living (ADL), $18.9 \%$ (10) needed intermittent supervision, and $37.7 \%$ (20) required constant supervision in the performance of these activities. Independence (no supervision required) in ADL in relation to cognitive impairment at discharge is shown in table 4.

Table 3 Results of FIM assessment

\begin{tabular}{|c|c|c|c|c|c|}
\hline & $\begin{array}{l}\text { Admission FIM mean } \\
\text { (motor+cognitive subscore) }\end{array}$ & $\begin{array}{l}\text { Discharge FIM mean } \\
\text { (motor+cognitive subscore) }\end{array}$ & FIM gain & $\begin{array}{l}\text { FIM gain/ } \\
\text { day }\end{array}$ & $\begin{array}{l}\text { FIM gain/ } \\
\text { week }\end{array}$ \\
\hline \multicolumn{6}{|l|}{ FIM total score: } \\
\hline All tested patients $(n=53)$ & $45.4(25.8+19.6)$ & $86.7(62.6+24.1)$ & 41.3 & 1.9 & 13.7 \\
\hline FIM total score: & & & & & \\
\hline Patients with severe cognitive impairment $(n=17)$ & $33.2(22.1+11.1)$ & $58.9(42+16.9)$ & 25.7 & 1.1 & 7.8 \\
\hline
\end{tabular}


Table 4 Independence in ADL in relation to cognitive impairment at discharge

\begin{tabular}{lll}
$\begin{array}{l}\text { Cognitive } \\
\text { impairment* }\end{array}$ & Total patients & $\begin{array}{l}\text { Independence in ADL } \\
\text { (No of patients (\%)) }\end{array}$ \\
\hline None & 19 & $19(100)$ \\
Mild & 11 & $4(36.4)$ \\
Severe & 17 & 0 \\
Total & 47 & 23 \\
\hline
\end{tabular}

*Grading according to results of mini mental examination (MMSE). $A D L$, activities of daily living.

Thirty eight $(64.4 \%)$ of the 59 patients were discharged home, $10(16.9 \%)$ were referred to a rehabilitation centre, five $(8.5 \%)$ to a long term care facility, and two $(3.4 \%)$ to other hospital departments. Four patients (6.8\%) died after surgery.

\section{DISCUSSION}

At present, there is no standardised method for measuring the deficits in patients with SAH. Likewise, it is not clear at what time postoperatively (time interval) it is best to determine the consequences of SAH. In recent years, numerous authors ${ }^{1-3} 6^{8-10}$ have established that patients who have recovered from surgery for SAH do not have major motor impairments which would prevent them from returning to work and reintegrating into the social enviroment. However, they note that diffuse cognitive impairments are manifested by a large percentage of patients, and that these impairments are the reason for the difficulties experienced in reintegrating the patients into the environment. For this reason, they are increasingly abandoning the earlier method of assessing these patients according to the Glasgow outcome scale (GOS). ${ }^{4} 7^{13} 14$ It has been shown that many patients classified as having made a good neurological recovery, have cognitive impairments. Many authors have attempted to establish the structure of cognitive impairments by means of a battery of specific neuropsychological tests. ${ }^{811}{ }^{12}{ }^{14}$ It is clear that all these tests are most useful for obtaining knowledge and detailed information on the type and extent of the deficits. Nevertheless, for everyday practice they are unsuitable and overdemanding. The problem with which rehabilitational medicine is confronted with increasing frequency is that of the importance of the preserved cognitive functions for the patient's independent socioeconomic functioning in society. ${ }^{18-21}$ For a long time it had been considered that the preserved motor ability was sufficient for attaining independence in performing the basic daily activities. Consequently, the assessment of the patients was also primarily directed towards determining the presence of motor deficits.

Through our study, we have endeavoured to find answers to the problems presented above, and ultimately to propose a simple but efficacious model for the early assessment of patients after SAH. The test group of patients is appropriate for several reasons. It comprises all the patients operated on at one neurosurgical department during the course of a single year. The age distribution is comparable with the existing literature, although the male/female ratio is somewhat different. The distribution of the aneurysms' localisation in the group shows similarities with some other series. ${ }^{237}$ By the time of discharge from hospital, most patients had achieved a good functional status, and $72.7 \%$ (40 out of 53 ) were without any motor impairment. However, $60.4 \%$ (32 of 53 ) were not yet oriented to time, person or situation, and $59.6 \%$ (28 of the 47 ) patients evaluated with MMSE had some kind of cognitive impairment.

The relevance of the preserved cognitive functions in attaining independence in the performance of basic daily activities (ADL) is presented in table 4. All patients without cognitive deficits attained independence in performing ADL. Patients presenting severe cognitive deficits, however, were all non-independent.

A more precise assessment of functional independence is provided by the values of the FIM assessment, which has proved to be extremely useful measure, as in assessing functional independence it also takes into account the cognitive state. The results in table 3 show that patients with lower MMSE ratings had a lower value of admission and discharge FIM, and that their progress was slower (lower FIM gain).

These results demonstrate the need to take into account the cognitive state in assessing the functional status of patients after SAH. The results of our study show that our approach to the assessment of patients by applying the FIM and MMSE tests is appropriate. It is sensible to include all operated patients in the early rehabilitation programme, and to assess their functional status as already it is possible to determine those patients who will require further rehabilitation and more detailed neuropsychological diagnostics and therapy.

\section{CONCLUSION}

Surgery has significantly improved the outcome of patients with ruptured aneurysms. The cognitive and behavioural impairments caused by aneurismal SAH are often more disabling than the physical sequel. Neuropsychological assessment and treatment should play an important part in all phases of recovery, including the initial phase after aneurysm rupture and surgery. Early inpatient rehabilitation should be provided for all patients. At discharge from hospital, the rehabilitation team must inform the patient and relatives about further treatment possibilities (for example, continued cognitive and behavioural therapy) and the available social and rehabilitation services. It is also important to make arrangements for follow up assessments, which will allow the team to evaluate the patient's further progress and social functioning as well as to gather valuable information to be used in planning all stages of rehabilitation treatment for SAH survivors.

\section{ACKNOWLEDGEMENTS}

We thank all the surgeons from the Department of Neurosurgery, University Medical Centre, Ljubljana, and especially Professor Vinko V Dolenc, for support and cooperation. The use of the FIM ${ }^{\mathrm{TM}}$ instrument to collect data for this research study was authorised and conducted in accordance with terms of a special purpose licence granted to the licencee by the Uniform Data System for Medical Rehabilitation (a division of UB Foundation Activities Inc, UDSMR). The licence has not been trained or certified by UDSMR in the use of the FIM ${ }^{\mathrm{TM}}$ instrument, and the patient data collected during the course of this research study has not been submitted to or processed by UDSMR. No implication is intended that such data has been or will be subjected to USSMR standard data processing procedures or that it is otherwise comparable with data processed by UDSMR.

Authors' affiliations

B M Saciri, Institute for Rehabilitation, Republic of Slovenia, Linhartova 51, 1000 Ljubliana, Slovenia

N Kos, Medical Rehabilitation Unit, University Medical Centre Ljubljana, Zaloska 7, 1000 Ljubliana, Slovenia

\section{REFERENCES}

1 Mayberg MR, Batjer HH, Dacey R, et al. Guidelines for the management of aneurysmal subarachnoid haemorrhage. Stroke 1994;25:2315-28.

2 Dombovy ML, Drew-Cates J, Serdans R. Recovery and rehabilitation following subarachnoid haemorrhage. Part I: outcome after inpatient rehabilitation. Brain Inj 1998;12:443-54.

3 Clinchot MD, Bogner JA, Kaplan PE. Cerebral aneurysms: analysis of rehabilitation outcomes. Arch Phys Med Rehabil 1997;78:346-9.

4 Säveland $H$, Brandt $L$. Which are the major determinants for outcome in aneurysmal subarachnoid hemorrhage? A prospective total management study from a strictly unselected series. Acta Neurol Scand 1994;90:245-50. 
5 Ogden JA, Mee EW, Henning M. A prospective study of impairment of cognition and memory and recovery after subarachnoid hemorrhage. Neurosurgery 1993;33:572-87.

6 Dombovy ML, Drew-Cates J, Serdans R. Recovery and rehabilitation following subarachnoid haemorrhage. Part II: long-term follow-up. Brain Inj 1998; 12:887-94.

7 Säveland H, Hillman J, Brandt L, et al. Overall outcome in aneurysmal subarachnoid hemorrhage. J Neurosurg 1992;76:729-34.

8 Germano A, Caruso G, Caffo $M$, et al. Does subarachnoid blood extravasation per se induce long term neuropsychological and cognitive alterations?. Acta Neurochir (Wien) 1998;140:805-11.

9 Sonesson B, Ljunggren B, Saveland $\mathrm{H}$, et al. Cognition and adjustment after late and early operation for ruptured aneurysm. Neurosurgery 1987;21:279-87.

10 Sonesson B, Saveland $\mathrm{H}$, Ljunggren B, et al. Cognitive functioning after subarachnoid haemorrhage of unknown origin. Acta Neurol Scand 1989;80:400-10.

11 Barbarotto R, De Santis A, Laiacona M, et al. Neuropsychological follow-up of patients operated for aneurysms of the middle cerebral artery and posterior communicating artery. Cortex 1989;25:275-88.

12 Laiacona M, De Santis A, Barbarotto R, et al. Neuropsychological follow-up of patients operated for aneurysms of anterior communicating artery. Cortex 1989;25:261-73.
13 Hütter BO, Kreitschmann- Andermahr I, Gilsbach JM. Cognitive deficits in the acute stage after subarachnoid hemorrhage. Neurosurgery 1998;43: 1054-65.

14 Bornstein RA, Weir BK, Petruk KC, et al. Neuropsychological function in patients after subarachnoid hemorrhage. Neurosurgery 1987;21:651-4.

15 Fiedler RC, Granger CV. Uniform data system for medical rehabilitation. Report of first admissions for 1996. Am J Phys Med Rehabil 1998:77:69-75.

16 Guide for the uniform data set for medical rehabilitation (including the FIM instrument), Version 5.1. Buffalo, NY 14214: State University of NewYork at Buffalo, 1997

17 Jensterle J, Mlakar J, Vodušek DB. Mini mental state and assessment of dementia syndrome. Zdrav Vestn 1996;65:577-82.

18 Clinchot MD, Kaplan P, Murray DM, et al. Cerebral aneurysms and arteriovenous malformation: implications for rehabilitation. Arch Phys Med Rehabil 1994;75:1342-51

19 Kaplan CP, Corrigan JD. The relationship between cognition and functional independence in adults with traumatic brain injury. Arch Phys Med Rehabil 1994;75:643-7.

20 Hutter BO, Kreitschmann- Andermahr I, Mayfrank L, et al. Functional outcome after aneurysmal subarachnoid hemorrhage. Acta Neurochir Suppl (Wien) 1999;72:157-74.

21 Hop JW, Rinkel GJ, Algra A, et al. Quality of life in patients and partners after aneurysmal subarachnoid hemorrhage. Stroke 1998:29:798-804

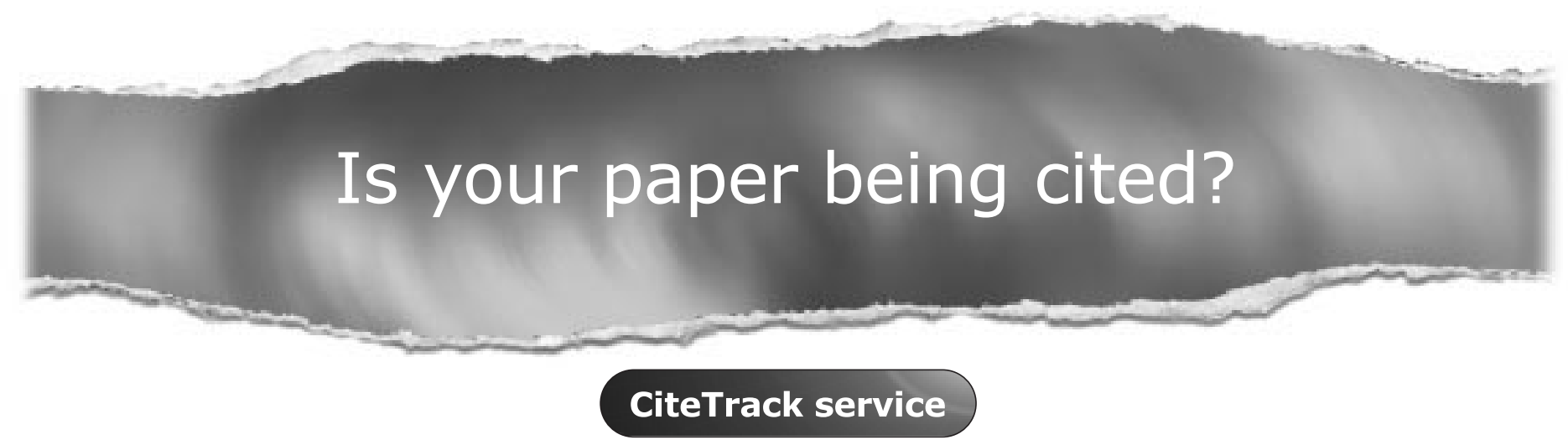

CiteTrack will alert you by email whenever new content in the Journal of Neurology, Neurosurgery, and Psychiatry or a participating journal is published that matches criteria you want to track Topics: Tell CiteTrack which words or subjects to watch for in new content Authors: Be alerted whenever key authors you are following publish a new paper Articles: Know whenever a paper of interest to you is referenced by another paper

\section{www.jnnp.com}

